\title{
Promoção da saúde através da educação popular e práticas corporais: potencializando o cuidado e fortalecendo os vínculos sociais
}

\section{RESUMO}

As ações de promoção à saúde podem servir como estratégia de fomento da democracia e participação social, e desse modo, a criação de grupos de promoção de saúde vinculados a perspectiva da Educação Popular passa a ter um papel fundamental na democracia participativa. Este trabalho relata a formação de um grupo de promoção de saúde com ações pautadas na Educação Popular em saúde e nas práticas corporais realizado por residentes do Programa de Residência Multiprofissional em Atenção Básica/ Saúde da Família de uma Universidade. Este grupo, denominado "Movimenta SUS", formou-se como um grupo multiprofissional com o intuito de cuidado integral, para trabalhar ações de educação popular e práticas corporais. A experiência permitiu o fortalecimento do vínculo, da autonomia, do cuidado de si e do outro, da utilização de espaços públicos, do sentimento de pertencimento, identidade cultural, da construção de uma consciência crítica e a experimentação de diferentes experiências.

PALAVRAS-CHAVE: Promoção de saúde; Participação popular; Educação popular em saúde; Atenção básica; Práticas corporais
João Batista de Oliveira Junior Doutorando em Saúde Coletiva e Mestre em Saúde Coletiva Universidade Federal de Santa Catarina UFSC Departamento de Saúde Pública Florianópolis, Santa Catarina, Brasil jj.educauel@gmail.com

${ }^{\circledR}$ https://orcid.org/0000-0002-4232-8165

Luana Bertamoni Wachholz

Mestre em Saúde e Gestão do Trabalho Universidade do Vale do Itajaí - UNIVALI Itajaí, Santa Catarina, Brasil luana_univali.br [D https://orcid.org/0000-0003-0441-107X

George Saliba Manske Doutor em Educação

Universidade do Vale do Itajaí - UNIVALI Programa de Pós-Graduação em Educação (PPGEDU) e Saúde e Gestão do Trabalho (PPGSGT)

Itajaí, Santa Catarina, Brasil gsmanske@yahoo.com.br

(1) https://orcid.org/0000-0003-0117-7927

Fernanda Cornelius Lange Mestranda em Saúde Coletiva

Universidade Federal de Santa Catarina UFSC Departamento de Saúde Pública Florianópolis, Santa Catarina, Brasil fernandalange@yahoo.com.br https://orcid.org/0000-0002-9037-6233 
Health promotion through popular education and corporal practices: enhancing care and strengthening social bonds

\begin{abstract}
Health promotion actions can serve as a strategy to promote democracy and social participation, and thus, the creation of health promotion groups linked to the perspective of Popular Education has a fundamental role in participatory democracy. This paper reports the formation of a health promotion group with actions based on Popular Education in health and corporal practices carried out by residents of the Multiprofessional Residency Program in Primary Care / Family Health of a University. This group, called "Movimenta SUS", was formed as a multiprofessional group with the purpose of integral care, to work on popular education actions and corporal practices. The experience allowed the strengthening of the bond, autonomy, care of oneself and the other, the use of public spaces, the feeling of belonging, cultural identity, the construction of a critical conscience and the experimentation of different experiences.
\end{abstract}

KEYWORDS: Health promotion; Community participation; Popular education in health; Primary health care; Corporal practices

Promoción de la salud a través de la educación popular y prácticas corporales: potenciando el cuidado y fortaleciendo los vínculos sociales

\title{
RESUMEN
}

Las acciones de promoción a la salud pueden servir como estrategia de fomento de la democracia y participación social, y de ese modo, la creación de grupos de promoción de salud vinculados a la perspectiva de la Educación Popular pasa a tener un papel fundamental en la democracia participativa. Este trabajo relata la formación de un grupo de promoción de salud con acciones pautadas en la Educación Popular en salud y en las prácticas corporales realizado por residentes del Programa de Residencia Multiprofesional en Atención Básica / Salud de la Familia de una Universidad. Este grupo, denominado "Movimenta SUS", se formó como un grupo multiprofesional con el propósito de cuidado integral, para trabajar acciones de educación popular y prácticas corporales. La experiencia permitió el fortalecimiento del vínculo, de la autonomía, del cuidado de sí y del otro, de la utilización de espacios públicos, del sentimiento de pertenencia, identidad cultural, de la construcción de una conciencia crítica y la experimentación de diferentes experiencias.

PALABRAS-CLAVE: Promoción de salud; Participación popular; Educación popular en salud; Atención básica; Prácticas corporales 


\section{INTRODUÇÃO}

O Sistema Único de Saúde (SUS) constitui um modelo de ações públicas e serviços de saúde no Brasil, caracterizando assim uma grande conquista social, criado para promover a justiça social e superar as desigualdades na assistência à saúde da população. A conquista desse sistema se dá a partir de um movimento social formado por diferentes atores sociais que resultaram no movimento de Reforma Sanitária, o qual evidenciou a necessidade da mobilização popular para incluir a saúde como prioridade nas políticas públicas (MENICUCCI, 2014).

Esses atores, reunidos na VIII Conferência Nacional de Saúde, colocaram em pauta uma proposta bem definida e clara de reforma à saúde. Dessa forma, o SUS foi instituído pela Constituição Federal de 1988 (BRASIL, 1988) e implantado no início da década de 1990, após a promulgação da Lei Orgânica da Saúde (Lei n. 8.080 de 19 de setembro de 1990, complementada pela Lei n. 8.142, de 28 de dezembro 1990) colocando a saúde (no seu sentido ampliado) como direito de todos, dever do Estado, e um sistema com princípios universalistas e igualitários.

A Lei $n^{\circ} 8.142 / 90$ dispõe sobre a participação da comunidade na gestão do SUS, porém, o que se têm visto nos últimos 27 anos desde sua implementação é que o SUS que foi sonhado não é aquele que temos na prática. O momento político de redemocratização vivido pelos brasileiros, evidenciado pela queda do regime militar e conquista de uma constituição cidadã, com grande fertilidade para movimentos sociais foi sendo destruída por seguidos governos neoliberais que retiraram aos poucos o espaço da organização popular (TESSER JÚNIOR et al, 2016).

Dessa forma, se faz necessário estratégias para fomentar a participação social, bem como ações envolvendo a promoção da saúde, pois para a conquista de um SUS universal, integral e equânime, assim como para uma transformação de sociedade, torna-se fundamental uma intensa mobilização social aliada a embates políticos e uma ampla disputa ideológica.

Sendo assim, as ações de promoção à saúde podem servir como estratégia de fomento da democracia e participação social, entendendo este termo como:

Parte de uma concepção ampla do processo saúde-doença e de seus determinantes, estando associada a um conjunto de valores que inclui: qualidade de vida, saúde, solidariedade, equidade, democracia, cidadania, desenvolvimento, participação, entre outros. Apresenta como elementos essenciais a articulação de saberes técnicos e populares e a mobilização de recursos institucionais e comunitários para o enfrentamento e resolução dos problemas de saúde (BUSS, 2000. p.23).

As associações comunitárias e os grupos sociais têm papel importante no atual momento político e social que vivemos, visto que estes podem implicar na socialização das pessoas; na 
integração e transformação social; nas suas capacidades de impulsionar o desenvolvimento econômico; fomentar o sentimento de pertencimento e a identidade cultural entre outras potencialidades (LUCHMANN, 2014).

Desse modo, a criação de grupos de promoção de saúde vinculados à perspectiva da Educação Popular de Paulo Freire passa a ter um papel fundamental no incremento da democracia participativa, pois a Educação Popular em Saúde (EPS) se constitui como estratégia capaz de disseminar o saber e apoiar os processos de redução das desigualdades e das iniquidades sociais, pela participação ativa dos sujeitos na construção de processos educacionais mais próximos de suas realidades de vida (PEDROZA, 2007).

As ações de grupo em saúde são uma ferramenta importante para abordagem de questões referentes ao processo saúde doença na APS, especialmente as ações que priorizam intervenções de suporte social, na medida em que por diferentes estratégias permitam a produção de autonomia nas ações de saúde, possibilitando e potencializando o enfrentamento do processo de medicalização, tanto em âmbito individual quanto no coletivo na APS, bem como nos serviços do SUS em geral (TESSER et al, 2015).

A EPS apresenta alguns desafios na política pública de saúde e na prática social para o avanço da democracia participativa, assegurando o SUS como garantidor do acesso às ações de saúde e fundamentalmente instituído por valores capazes de promover relações mais humanizadas, formação da consciência crítica, promoção da autonomia, trabalho social emancipatório e à superação das desigualdades sociais. Na perspectiva da EPS, a cultura popular é valorizada pelo respeito às iniciativas, ideias, sentimentos e interesses de todas as pessoas, assim como na inclusão de tais elementos como fios condutores do processo de construção do trabalho e da formação (BENETTI et al, 2014).

O SUS tem na Atenção Básica (AB) sua porta de entrada, e a Estratégia Saúde da Família (ESF) como estratégia para atendimento integral e equânime, com a incorporação de outras práticas e saberes no campo da saúde pública. Com a implantação em 2008 do Núcleo de Apoio à Saúde da Família (NASF) ${ }^{1}$, alguns profissionais foram inseridos no contexto da $\mathrm{AB}$, com o intuito de consolidar e fortalecer a AB e as ESF (BRASIL, 2011). O profissional de educação física pode fazer parte do NASF, e juntamente com outros profissionais, através de um trabalho interdisciplinar, é fundamental para desenvolver ações pautas na Promoção da Saúde (MELO et al, 2018).

\footnotetext{
${ }^{1}$ Em 2008 o serviço foi instituído com a nomenclatura Núcleo de Apoio a Saúde da Família (NASF) pela portaria ${ }^{\circ}$ 154/2008, porém, a portaria $n^{\circ} 2.436$, de 21 de setembro de 2017 alterou o nome para Núcleo Ampliado de Saúde da Família (NASF- AB)
} 
Cabe destacar que apesar das diretrizes para ações de desenvolvimento de promoção da saúde no SUS indicarem atuação popular de forma ativa e participativa em seus próprios processos de saúde-doença, corroborando para práticas que gerem autonomia dos sujeitos nas relações consigo mesmos e comunidades, tal como subsidiam propostas calcadas na EPS, por exemplo, as ações concernentes a atuação da educação física, historicamente, tem sido pautadas por outros modelos de atuação (BAGRICHEVSKY et al, 2006; GOMES, FRAGA, CARVALHO, 2015).

No âmbito das ações da educação física na saúde pública as atividades físicas e os exercícios físicos tem sido o carro chefe das atividades desenvolvidas, e isso se deve, sobretudo, aos modelos biologicistas que se centram em diagnósticos e resultados de ordem fisiológica nos corpos dos indivíduos. Uma série de estudos e autores tem alertado para tais modelos prescritivos e preventivistas das atividades físicas e exercícios físicos, e proposto alternativas mais condizentes para ações da educação física na saúde pública que estejam alinhados com os princípios do SUS e considerem preceitos da saúde coletiva (BAGRICHEVSKY et al, 2006; GOMES, FRAGA, CARVALHO, 2015), inclusive demonstrando como operam na atualidade processos educativos financiados pelos Ministérios da Educação e Saúde para formações que suplantem os modelos tradicionais e se desenvolvam coadunados com o SUS (MANSKE et al, 2019)

Nesse ínterim, as práticas corporais (PC) surgem como uma ferramenta de atuação no SUS para os profissionais da Educação Física, pois parte de uma atuação nos moldes da Saúde Coletiva, pautados nos princípios do sistema.

Essas práticas ampliam as possibilidades de encontrar, escutar, observar e mobilizar as pessoas adoecidas para que, no processo de cuidar do corpo, elas efetivamente construam relações de vinculo, de corresponsabilidade, autônomas, inovadoras e socialmente inclusivas, de modo a valorizar e otimizar o uso dos espaços públicos de convivência e de produção de saúde, que podem ser os parques, as praças e as ruas. (CARVALHO, 2006, p.33$34)$.

Como base nisto, este trabalho teve por objetivo descrever a formação de um grupo de promoção de saúde com ações pautadas na educação popular em saúde e nas práticas corporais aplicadas ao mesmo. Busca também mostrar a potencialidade da educação popular, práticas corporais e do trabalho multiprofissional como potencializador do controle social e das possibilidades de intervenção para o trabalho de promoção de saúde na Atenção Básica. 


\section{METODOLOGIA}

Trata-se de um relato de experiência de natureza descritiva sobre a formação de um grupo de promoção de saúde na Atenção Básica, com ações pautadas nos princípios da educação popular em saúde e nas práticas corporais.

O grupo foi realizado por residentes do Programa de Residência Multiprofissional em Atenção Básica/ Saúde da Família, da Universidade do Vale do Itajaí - UNIVALI, inseridos no NASF do município de Itajaí - SC.

Atuando no NASF, os residentes das áreas de Educação Física, Fisioterapia, Psicologia, Fonoaudiologia e Farmácia juntamente com uma preceptora Nutricionista foram acionados pelas Estratégias de Saúde da Família (ESF) da Unidade Básica de Saúde (UBS) que atuavam com a solicitação da formação de um grupo de atividades físicas, voltado para a prevenção de doenças e reabilitação física.

Partindo de uma concepção de saúde ampliada e pautada na perspectiva da educação popular em saúde, os residentes formaram um grupo que pudesse ocorrer a realização de atividades físicas como foi solicitado pelas ESF, mas que fosse para além de benefícios biológicos, e para isso foi utilizado o conceito de práticas corporais (descrito anteriormente) na organização do grupo e suas ações.

\section{Caracterização do 'Movimenta Sus'}

Partindo dessa premissa, criou-se o grupo intitulado 'Movimenta SUS', o qual foi idealizado pelos residentes atuantes no NASF da UBS do município de Itajaí. O grupo acontecia duas vezes na semana, cada encontro tinha a duração média de duas horas. O relato acontece a partir de oito meses de duração do grupo (março a outubro de 2017), mas vale ressaltar que as atividades continuam após o relato.

As pessoas eram convidadas a participar a partir de consultas compartilhadas e visitas domiciliares realizadas por profissionais do NASF e pelos profissionais da ESF, no qual era identificado o grupo como adequado para aquela pessoa. Ao serem convidadas, as pessoas passavam por uma consulta compartilhada com os profissionais do NASF, com o intuito de conhecer sua história de vida, suas motivações e dúvidas quanto à participação no grupo, bem como aspectos físicos e psicossociais.

As atividades aconteciam em uma sala anexa a UBS e em uma praça do bairro que contava com academia ao ar livre, quadra de voleibol de praia, quadra poliesportiva e espaços ao ar livre que permitiam a realização de diversas práticas. 
As atividades desenvolvidas englobavam práticas corporais diversas, atividades físicas e exercícios físicos (alongamentos, caminhadas/ corridas, circuitos funcionais, prática de esportes, danças entre outros), recreativas (cafés, confraternizações), oficinas ministradas pelos participantes (artesanatos, culinária etc.), educação em saúde (abordando temas de acordo com o interesse e conhecimento dos participantes), passeios turísticos, visitas em outros grupos e participação em evento cultural. As ações realizadas foram estruturadas e organizadas de acordo com a percepção dos interesses e necessidades das pessoas que participavam.

A coleta de dados ocorreu a partir das atividades realizadas do grupo e junto aos participantes, sendo que os mesmos foram coletados de maneira contínua a partir da observação participante e de entrevistas informais, como formas de captar informações. A observação participante permitiu perceber atitudes e olhares que acompanhavam as falas das pessoas nos diferentes espaços e momentos do grupo, e também verificar a melhora de parâmetros biopsicossociais.

A partir desse processo realizou-se uma análise descritiva desde o material de registro produzido pelas entrevistas informais e das observações participantes, com o intuito de conhecer os impactos do grupo na vida das pessoas que dele participaram.

\section{Caracterização das pessoas participantes}

Após sua consolidação, o grupo tinha em média 15 pessoas que participavam ativamente, mas como era um grupo aberto, sempre havia novas pessoas se integrando. As pessoas envolvidas eram de faixas etárias distintas, entre 25 e 70 anos, com predomínio de pessoas idosas, na sua maioria mulheres que eram do lar, aposentadas, que utilizavam algum benefício social ou que estavam desempregadas.

\section{RESULTADOS E DISCUSSÃO}

O Movimenta SUS se formou como um grupo multiprofissional, com o intuito de cuidado integral, para juntamente com benefícios biológicos, trabalhar ações de educação popular e práticas corporais que eram fomentadas por todos residentes, fugindo de uma prática orientada por um modelo prescritivo, culpabilizante e moralizador.

Os encontros do grupo eram divididos em dois momentos, o primeiro era trabalhado atividades físicas, iniciando com caminhada, a qual tinha como objetivo mostrar a possibilidade da realização dessa atividade de forma autônoma, em detrimento de uma heteronomia de supervisão e indicação dos modos como realizá-la. A experiência nesse momento como a escuta e a 
comunicação durante a caminhada favorecia o cuidado e vinculação tanto entre profissionais e participantes, quanto entre os próprios participantes. Neste espaço também era possível verificar como as relações de poder entre profissionais e participantes podiam contribuir para produzir ou dificultar a produção de saúde, pois o desenvolvimento e abertura do diálogo, bem como o trabalho partilhado, são fundamentais para as relações produzidas (MENDES e CARVALHO, 2016).

Este momento também era indispensável para fomentar a utilização de espaços públicos e de pertencimento das pessoas para com esses locais, visando que a caminhada era realizada em uma praça do território adstrito da UBS. Essa experiência corrobora os achados de Beccalli e colaboradores (2016), que apresentam que as práticas corporais no campo da Saúde Coletiva têm o papel de fazer com que as pessoas se apropriem dos espaços sociais presentes no território, como praças, parques, calçadas entre outros, e que essa apropriação se dê para além do espaço geográfico propriamente dito, indo na direção de um espaço de produção de sentidos e subjetividades, sendo um espaço de promoção de saúde.

Ainda nesse primeiro momento eram realizados exercícios que se alternavam em circuitos funcionais, brincadeiras, jogos, danças circulares entre outros, atividades que pudessem trabalhar a coletividade, que fizessem sentido para as participantes. Para isso e pensando na perspectiva da EPS, que tem como um de seus princípios a participação ativa dos sujeitos na construção de processos educacionais, as atividades, jogos e brincadeiras realizadas foram levantadas juntamente com as participantes, coletadas de maneira explicita através de rodas de conversa, como também de maneira implícita, levantadas em outros momentos, como na caminhada, por exemplo (PEDROZA, 2007).

Para o segundo momento, o critério era privilegiar temas de interesse dos envolvidos, que foram demonstrados também de forma implícita ou explícita. A partir desses levantamentos realizaram-se rodas de conversa, práticas de meditação, respiração, automassagem, atividades de saúde mental, oficinas de plantas medicinais, cafés coletivos, práticas manuais, entre diversas outras.

Nas rodas de conversa e cafés coletivos foi possível trabalhar, através de princípios pautados na EPS, a problematização da realidade vivenciada pelos participantes, bem como seus enfrentamentos diante dos determinantes sociais da saúde, valorizando os saberes populares como forma de construir relações e vínculos mais efetivos, além da construção compartilhada do conhecimento, que implica o reconhecimento do outro em sua totalidade e diversidade (BENETTI et al, 2014). Além disso, a problematização realizada nesses momentos a partir da experiência dos participantes buscou desenvolver uma visão crítica, capaz de transformar o contexto de vida, tal 
como proposto por Freire (1987), que é a primeira fase para permitir a transformação do mundo (DANTAS; LINHARES, 2014).

Em um dos encontros, no segundo momento, realizou-se uma oficina de plantas medicinais, sendo possível trabalhar o saber cultural trazido pelos participantes, onde estes puderam trazer plantas que cultivavam em sua casa e que colhiam no território, compartilhar com os demais sobre seu modo de cultivo, preparo, ingestão, entre outros, sendo um momento de troca de saberes e valorização do conhecimento popular. Essa experiência é traço do círculo de cultura, proposto por Paulo Freire (1991), que vem com uma proposta pedagógica com características democráticas e libertadora, e segundo o autor, esse método pedagógico promove horizontalidade nas relações e a valorização das culturas locais, contrapondo-se a visão elitista da educação.

A atividade predominante nesse segundo momento foi a preparação de artesanatos, os quais eram ensinados pelos próprios participantes, fazendo com que valorizassem seus próprios conhecimentos, sendo uma das perspectivas da EPS e círculo da cultura como já exposto acima. Realizaram-se diversos tipos de artesanatos, onde em cada produção havia a condução por um ou mais participantes, pautado no conhecimento do objeto que estava sendo produzido.

Os participantes tinham atuação ativa no grupo, e quando faltavam, tinham a preocupação de avisar o motivo. Durante o caminho percorrido algumas participantes acabaram saindo por motivos variados, como a inserção no mercado de trabalho, compromissos pessoais, entre outros, e de modo semelhante, outros iniciaram a participação no grupo. Vale ressaltar que para a consolidação de um grupo fez-se necessário vários encontros, sendo ainda que a força do grupo se deu pela participação ativa de todos os atores envolvidos.

Um dos desdobramentos que ocorreu a partir do grupo foi a mobilização para a participação da IV Noite Cultural do bairro, a qual teve como objetivo expor os artesanatos produzidos pelo próprio grupo reforçando ainda a fomentação de pertencimento ao território, de coletividade e autonomia das pessoas. Vale destacar, também, como as pessoas passaram assumir a condução do grupo, assumindo o protagonismo de suas vidas a partir da experimentação de tais experiências (CARVALHO, 2010).

Destaca-se como ponto importante a mobilização dos participantes do grupo, os quais se envolveram em outras ações realizadas na UBS, fator este que reafirma o sentimento de pertencimento daquele espaço, sentimento esse tão enfatizado e que se mostra importante nas práticas de promoção da saúde, pois segundo Gohn (2004), grupos com pouca representatividade, laços de pertencimento e projetos frágeis, não são capazes de ampliar as relações democráticas e não colaboram para a justiça e emancipação popular. 
Além disso, alguns deles passaram a se inserir no grupo de participação social do bairro, com o intuito de resgate do conselho local de saúde desse território, mostrando assim o potencial de alcance político do grupo que faziam parte, permitindo, por meio da solidariedade, um processo de superação física e psicológica do âmbito individual para o coletivo, e também para um campo mais amplo, o social (SANTOS, et al 2006). Esse processo de concepção do social foi importante, pois através dele as pessoas podem ocupar um espaço político onde a sociedade possa assumir responsabilidades junto ao Estado no desenvolvimento de políticas públicas através de decisões autônomas, voltadas para o fortalecimento da democracia e do SUS (TESSER JÚNIOR et al, 2015).

Assim, como discutido por Mendes e Carvalho (2016), percebeu-se que é possível realizar encontros que favoreçam a ampliação das compreensões sobre relações, desejos, interesses, necessidades e as distintas maneiras de viver, ao contrário de uma autonomia funcional, centrada em uma visão instrumental do movimento.

\section{Reflexões a partir da experiência com o MovimentaSUS}

A vivência através do grupo possibilitou algumas reflexões, sendo que a primeira delas é sobre a importância da formação de profissionais para a atuação no SUS, pois uma das dificuldades encontradas no decorrer deste processo foi a falta de apoio dos demais profissionais da UBS, visando que o grupo foi constituído apenas por profissionais residentes que atuavam no NASF. Este modelo de atuação não corrobora a proposta de trabalho da Atenção Básica, o qual se materializa por meio do compartilhamento, da troca e da articulação entre profissionais do NASF e ESF (SANTOS et al, 2017).

A EPS emerge como um saber que contribui para formação de profissionais comprometidos com as questões sociais, que se preocupam com as lutas por direitos e democracia, bem como a diminuição das injustiças sociais. Além disso, possui posturas acolhedoras e de construção da autonomia das pessoas e dos grupos envolvidos (PEDROZA, 2007). Nesse contexto, as ações de Educação Permanente também são fundamentais entendendo que os profissionais estão em constante formação, ela aparece como uma proposta de ação estratégica para contribuir para a transformação e a qualificação das práticas de saúde (BRASIL, 2004).

Outra reflexão envolve os programas de Residência Multiprofissional, criados a partir da Lei $\mathrm{n}^{\mathrm{o}} 11.129$ de 2005 , os quais também apresentam o intuito de formar profissionais capacitados para a atuação no SUS, porém, esses profissionais, após a formação, ainda têm dificuldades de inserção no mercado. 
O horário de funcionamento da UBS, também se mostrou como uma barreira para a participação da população nas ações desenvolvidas, não estando de acordo com um dos princípios do SUS, a Universalidade, sendo que o horário é um dos fatores responsável pelo perfil dos participantes.

Outro ponto que se mostra importante é o conhecimento e valorização da cultura local, pois assim como trazido por Roio (2007), após analisar a teoria gramsciana de subalternidade e emancipação, é importante conhecer a cultura popular para entender os elementos de rebeldia e a reação desses subalternos em relação a dominação e, através disso, trabalhar pautado na promoção de saúde, na busca por autonomia e transformação social, em um modelo que faça sentido para a realidade daquela população.

\section{CONSIDERAÇÕES FINAIS}

Este trabalho relaciona alguns conceitos fundamentais com uma prática exitosa realizada em uma UBS por residentes multiprofissionais, com a intenção de mostrar ferramentas e métodos que tiveram aplicações bem-sucedidas, pressupondo novas interfaces de atuação no modelo de assistência à saúde, e procurando ir de encontro a modelos tradicionais prescritivos centrados em saberes especificamente de ordem biológica, e não cultural.

As práticas obtidas demonstram a importância do trabalho multiprofissional na realização de ações de promoção de saúde. A discussão teórica sobre os conceitos de educação popular e práticas corporais mostraram como tais conteúdos são fundamentais para o fortalecimento das ações. Esses conceitos teóricos foram adotados a partir de um estudo das necessidades desse território, sendo necessário uma adaptação para aplicação em outros contextos. Vale ressaltar ainda que o conceito de práticas corporais adotado neste trabalho ocorre a partir da concepção epistemológica baseada na saúde coletiva, visto que este conceito admite interpretações diversas. Além do mais, ressalta-se que as práticas corporais têm sido sugeridas como alternativas mais condizentes com os modelos de saúde adotados pelos SUS, em contraposição as realizações mais tradicionais da educação física nesse campo de atuação balizadas, sobretudo, pelas atividades físicas e exercícios físicos, esses inseridos em perspectivas teórico-metodológicas de cunho individual e biológico.

Especificamente nesse relato os conceitos contribuíram para a realização da promoção de saúde, em um grupo com propostas iniciais de atividade física e reabilitação para a prevenção de doenças. Tais abordagens contribuíram para o fortalecimento do vínculo, da autonomia, do cuidado de si e do outro, da utilização de espaços públicos, do sentimento de pertencimento, identidade cultural, da construção de uma consciência crítica e a experimentação de diferentes experiências, 
bem como de benefícios físicos e biológicos. Os grupos de promoção da saúde não garantem mudanças de comportamento, visando que esses trabalham em vista da complexidade humana, para que as mudanças sejam realizadas de maneira autônoma em condição de liberdade.

O momento social e político que vivemos demostra a importância da realização de práticas que possibilitem o fortalecimento da cidadania, tornando as pessoas capazes de participar, criticar e assumir o compromisso social. Por meio destes processos, os indivíduos e a coletividade constroem valores sociais, conhecimentos, atitudes e competências para a formação de uma consciência política, promovendo uma reflexão crítica sobre os modos de vida.

\section{REFERÊNCIAS}

BAGRICHEVSKY, Marcos et al (Org.). A Saúde em Debate na Educação Física - Volume 2. 1a. ed. Blumenau: Nova Letra, 2006. v. 1. 240p.

BECALLI, Michel Binda; GOMES, Ivan Marcelo. Práticas corporais/atividade física e saúde: da mobilização do sujeito ao movimento da constituição de espaços. In: WACHS, Felipe;

ALMEIDA, Ueberson Ribeiro; BRANDÃO, Fabiana F Freitas. Educação física e saúde coletiva: cenários, experiências e artefatos culturais. p. 199-222, 2016.

BENETTI, Osvaldo Peralta; CHAGAS, Reginaldo Alves; SIQUEIRA, Theresa Cristina.Albuquerque. A Educação Popular em Saúde na Gestão Participativa do SUS: construindo uma política. In: BRASIL. II Caderno de educação popular em Saúde. DF: Ministério da Saúde, 2014.

BRASIL. Constituição (1988). Constituição da República Federativa do Brasil. Brasília: Senado Federal, 1988.

BRASIL. Ministério da Saúde. Portaria n. ${ }^{\circ} 198$ GM/MS, de 13 de fevereiro de 2004. Institui a Política Nacional de Educação Permanente em Saúde como estratégia do SUS para a formação e o desenvolvimento de trabalhadores para o setor e dá outras providências. Brasília, Ministério da Saúde, 2004.

BRASIL. Portaria n. 2.488, de 21 de outubro de 2011. Aprova a Política Nacional de Atenção Básica, estabelecendo a revisão de diretrizes e normas para a organização da Atenção Básica, para a Estratégia Saúde da Família (ESF) e o Programa de Agentes Comunitários de Saúde (PACS). Brasília, Diário Oficial da União, Seção I, p. 48, Col. 1, de 24 de Out. 2011.

BUSS, Paulo Marchiori. Saúde, Sociedade e qualidade de vida. Ciência e Saúde coletiva, v.5, p. 163-177, 2000.

CARVALHO, Yara Maria. Promoção da saúde, praticas corporais e atenção básica. Revista Brasileira de Saúde da Família (Brasilia), v. VII, p. 33-45, 2006. 
CARVALHO, Yara Maria de. As práticas corporais como práticas de saúde e de cuidado no contexto da promoção da saúde. Tese (Livre docência). Faculdade de Saúde Pública, Universidade de São Paulo, São Paulo, 2010.

DANTAS, Vera Lucia; LINHARES, Angela Maria Bessa. Círculos de Cultura: problematização da realidade e protagonismo popular. In: BRASIL. II Caderno de educação popular em Saúde. DF: Ministério da Saúde, 2014.

FREIRE, Paulo. Educação como prática de liberdade. 20. ed. Rio de Janeiro: Paz e Terra, 1991.

FREIRE, Paulo. Pedagogia do oprimido. Rio de Janeiro: Editora Paz e Terra, 1987.

GOHN, Maria da Gloria. Empoderamento e participação da comunidade em políticas sociais. Saúde e Sociedade, 2004.

GOMES, Ivan; FRAGA, Alex Branco; CARVALHO, Yara Maria (orgs). Práticas Corporais no Campo da Saúde: uma política em formação [recurso eletrônico] - Porto Alegre : Rede UNIDA, 2015.

LUCHMANN, Lígia Helena. Abordagens teóricas sobre o associativismo e seus efeitos democráticos. Revista Brasileira de Ciências Sociais. São Paulo, v. 29, n. 85, p. 159-178. Junho 2014.

MANSKE, George et al. Concepções de Saúde e de Atuação Profissional dos Residentes de Educação Física de uma Residência Multiprofissional em Saúde. Tempos e Espaços em Educação v. 12, p. 261-274, 2019.

MELO, Eduardo Alves; MIRANDA, Lilian; SILVA, Atila Mendes; LIMEIRA, Rosana Mira Nunes. Dez anos dos Núcleos de Apoio à Saúde da Família (NASF): problematizando alguns desafios. Saúde debate, v. 42, número especial 1, p. 328-340, 2018.

MENDES, Valeria Monteiro; CARVALHO, Yara Maria. Práticas corporais e clínica ampliada: experimentando tessituras para a composição de outros modos de cuidado. In: WACHS, Felipe; ALMEIDA, Ueberson Ribeiro; BRANDÃO, Fabiana F Freitas. Educação física e saúde coletiva: cenários, experiências e artefatos culturais [recurso eletrônico]. p. 169-198, 2016.

MENICUCCI, Telma Maria Gonçalves. História da reforma sanitária brasileira e do Sistema Único de Saúde: mudanças, continuidades e a agenda atual. Hist. cienc. Saúde - Manguinhos, Rio de Janeiro, v. 21, n. 1, p. 77-92, 2014.

PEDROZA, José Ivo dos Santos. Educação Popular no Ministério da Saúde: identificando espaços e referências. In: BRASIL. Caderno de educação popular em Saúde. Brasília, DF: Ministério da Saúde, 2007.

ROIO, Marcos Del. Gramsci e a emancipação do subalterno. Revista Sociologia e Política. Curitiba, n. 29, p. $63-78,2007$.

SANTOS, Luciane Medeiros et al. Grupos de promoção à saúde no desenvolvimento da autonomia, condições de vida e saúde. Revista de Saúde Pública / Journal of Public Health, em prelo no 4810 - 29-06-05, v. 40, p. 346-352, 2006. 
SANTOS, Rosimeire Aparecida Bezerra de Gois dos; UCHOA-FIGUEIREDO, Lúcia da Rocha; LIMA, Laura Câmara. Apoio matricial e ações na atenção primária: experiência de profissionais de ESF e Nasf. Saúde debate, Rio de Janeiro, v. 41, n. 114, p. 694-706, 2017.

TESSER JÚNIOR, Zeno Carlos et al. Associativismo civil e saúde: uma revisão de literatura. In: Jornadas Bolivarianas, Florianópolis, XII Edição. 2016

TESSER JÚNIOR, Zeno Carlos et al. O papel do associativismo político na promoção de saúde. Saúde e Transformação social, 2015.

\section{NOTAS DE AUTOR}

\section{AGRADECIMENTOS}

Agradecemos a todas pessoas envolvidas na realização do MovimentaSUS, desde todos os profissionais envolvidos no processo, seja na idealização, construção ou realização do mesmo, em especial, às profissionais residentes Alice Marli Moratelli - psicóloga; Luciano Bernardes Júnior - fisioterapeuta; Gabriela Thaís da Silva - fonoaudióloga e Priscila Falaster da Costa farmacêutica, que participaram de todo o processo e que sem os mesmos não seria possível viabilizá-lo. Não poderíamos deixar de agradecer cada pessoa da comunidade que participou do grupo e que juntamente com os profissionais contribuíram para construir uma história rica e transformadora.

\section{CONTRIBUIÇÃO DE AUTORIA}

Concepção do manuscrito: J. B. Oliveira Junior, L. B. Wachholz, G. S. Manske, F. C. Lange Coleta de dados: J. B. Oliveira Junior, F. C. Lange

Análise de dados: J. B. Oliveira Junior, L. B. Wachholz, G. S. Manske, F. C. Lange

Discussão dos resultados: J. B. Oliveira Junior, L. B. Wachholz, G. S. Manske, F. C. Lange

Produção do texto: J. B. Oliveira Junior, L. B. Wachholz, G. S. Manske, F. C. Lange

Revisão e aprovação: J. B. Oliveira Junior, L. B. Wachholz, G. S. Manske, F. C. Lange

\section{FINANCIAMENTO}

Não se aplica.

\section{CONSENTIMENTO DE USO DE IMAGEM}

Não se aplica.

\section{APROVAÇÃO DE COMITÊ DE ÉTICA EM PESQUISA}

Não se aplica.

\section{CONFLITO DE INTERESSES}

Não há conflito de interesses.

\section{LICENÇA DE USO}

Os autores cedem à Motrivivência - ISSN 2175-8042 os direitos exclusivos de primeira publicação, com o trabalho simultaneamente licenciado sob a Licença Creative Commons Attribution Non-Comercial ShareAlike (CC BY-NC SA) 4.0 International. Esta licença permite que terceiros remixem, adaptem e criem a partir do trabalho publicado, desde que para fins não comerciais, atribuindo o devido crédito de autoria e publicação inicial neste periódico desde que adotem a mesma licença, compartilhar igual. Os autores têm 
autorização para assumir contratos adicionais separadamente, para distribuição não exclusiva da versão do trabalho publicada neste periódico (ex.: publicar em repositório institucional, em site pessoal, publicar uma tradução, ou como capítulo de livro), com reconhecimento de autoria e publicação inicial neste periódico, desde que para fins não comerciais e compartilhar com a mesma licença.

\section{PUBLISHER}

Universidade Federal de Santa Catarina. Programa de Pós-Graduação em Educação Física. LaboMídia Laboratório e Observatório da Mídia Esportiva. Publicado no Portal de Periódicos UFSC. As ideias expressadas neste artigo são de responsabilidade de seus autores, não representando, necessariamente, a opinião dos editores ou da universidade.

\section{EDITORES}

Mauricio Roberto da Silva, Giovani De Lorenzi Pires, Rogério Santos Pereira

\section{HISTÓRICO}

Recebido em: 27 de maio de 2019.

Aprovado em: 08 de outubro de 2019. 